\title{
Formação e prática docentes e seus desafios
}

\author{
Ruberval Rodrigues de Sousa \\ UFT/SEDUC/TO
}

Thyago Phellip França Freitas
UFT/SEDUC/TO/ULBRA/TO

\begin{abstract}
Resumo
Este estudo discute a formação e prática docentes no Brasil e os desafios existentes nos cursos de licenciaturas que destoam do modelo de educação ideal, onde a realidade encontrada nas salas de aulas dificulta a prática docente e colabora com os baixos índices da educação brasileira, principalmente a básica. A pesquisa discorre sobre o papel do estágio supervisionado na formação docente, bem como ressalta a necessidade de novos paradigmas educacionais, com novas metodologias, novos posicionamentos que contextualizem as práticas docentes com a realidade contemporânea. A busca pelo conhecimento encontra cada vez mais desafios em função das transformações pelas quais passa a sociedade. A ruptura com o modelo tradicional de ensino, a reformulação dos currículos escolares e dos cursos de formação, a partir da inserção da inter, trans e multidisciplinaridade podem ajudar a combater o conhecimento fragmentado/especializado, e promover uma educação com mais qualidade.

Palavras-chave: formação docente; prática docente; desafios.
\end{abstract}

\begin{abstract}
This study discusses the training and practice teaching in Brazil and the challenges in undergraduate courses that clash with the ideal education model, where the reality in the classrooms makes teaching practice difficult and contributes to the low ratings of Brazilian education, especially in the early years. The research discusses the role of supervised training in teacher development $_{2}$ and it highlights the need for new educational paradigms, with new methodologies, and new positions that contextualize teaching practices within contemporary reality. The quest for knowledge faces increasing challenges from the transformations undergone by society. The break with the traditional model of education and the reformulation of curricula and training courses, through the insertion of inter, trans and multidisciplinarity, may help combat the knowledge that is fragmented or specialized and promote a higher quality education.
\end{abstract}

Keywords: Teacher education. Teaching practice. Challenges.Challenges. 


\section{INTRODUÇÃO}

A formação docente ainda se encaminha para o enfretamento dos inúmeros desafios trazidos pelo momento social, econômico, cultural, etc.; isso requer do professor a habilidade de reinventar-se a todo tempo, e assim tornar-se multiprofissional. Ademais, são muitas adversidades que interferem na qualidade do ensino e que vão além da formação, passam pelas condições de trabalhos diversas, pela estruturação física das unidades escolares e ainda pela heterogeneidade advinda dos diversos níveis de conhecimento dos estudantes em uma mesma turma.

São inúmeros os dilemas enfrentados pela educação brasileira que, por seu perfil de constante construção e evolução, chama à atenção de estudiosos que buscam entender os fenômenos envolvendo a formação docente no Brasil. Com isso, o foco deste estudo está direcionado para os desafios da formação e atuação docente, bem como os impactos que esses desafios trazem para a qualidade do ensino-aprendizagem na educação básica brasileira.

Este estudo discute ainda o caráter contínuo da formação docente e a necessidade de interação curricular com a prática cotidiana dos aprendizes. Tratando sobre um saber heterogêneo percebe-se a importância da interdisciplinaridade, transdisciplinaridade e multidisciplinaridade no modelo educativo exigido pelo mundo moderno.

Estudar o processo de formação docente é um fazer contínuo, pois a realidade vivida no momento é determinante para a elaboração de práticas educacionais que efetivamente surtam efeito na formação do indivíduo, assim, este artigo pretende discutir exatamente o distanciamento entre a teoria e a prática no processo educacional brasileiro, bem como refletir sobre a falta de conexão entre os ensinamentos nas licenciaturas e a realidade a ser encarada pelos seus egressos, os professores, nas múltiplas realidades da educação brasileira.

O professor é peça fundamental na formação social do indivíduo e na construção da própria sociedade, uma vez que, para se obter qualquer nível de formação, em qualquer área, é necessária a atuação de professores. Há que se refletir, portanto, sobre o contexto que esses profissionais, docentes ou não, irão atuar, despertando assim o interesse pela busca de novos conhecimentos e novas metodologias que propiciem o diálogo entre a teoria e a prática adotadas. 


\section{A COMPLEXIDADE NA FORMAÇÃO E PRÁTICA DOCENTES}

A sociedade vem passando por transformações de ordens diversas ao longo dos anos, e isso suscita constantes reformulações dos saberes e das práticas cotidianas. Seria inimaginável pensar o processo de ensino-aprendizagem dissociado da evolução tecnológica. Aprender e ensinar implica cada vez mais em complexidades existentes entre a teoria e a prática, sendo o principal desafio docente promover a interação dos conteúdos escolares com as vivências do dia a dia dos estudantes.

Em se tratando de educação, mais especificamente de formação e prática docentes, mesmo aqueles professores que não tiveram a oportunidade de ampliar seus conhecimentos em uma universidade durante o seu processo de formação, seus planejamentos e ações em sala de aula os levam a uma constatação de que existem gargalos na docência que lhes exigem repensar sobre os desafios da educação atual, como descrito por Maria Cândida Moraes em sua obra Paradigma Educacional Emergente (2011), na Introdução ao Pensamento Complexo de Edgar Morin (2008) e em O Sonho Transdisciplinar de Hilton Japiassu (2006), dentre outros.

As instituições de ensino superior têm os seus Projetos Políticos Pedagógicos alicerçados na tríade ensino, pesquisa e extensão, como elementos garantidores da qualidade do ensino que ofertam. Entretanto, estes elementos não parecem ser suficientes para darem tal garantia, em função de haver outros quesitos a serem levados em consideração acerca da formação inicial, como trabalhar a habilidade dos egressos das licenciaturas na integração entre os saberes das disciplinas específicas com práticas pedagógicas capazes de instigar ações docentes mais eficazes.

Esta estratégia de formação prepara os profissionais para serem capazes de transitar por campos e áreas diversos e assim contribuir ainda mais com o aprendizado dos seus alunos.

Defendendo a transdisciplinaridade e discorrendo sobre o engessamento patrocinado por um processo de formação docente fechado por disciplinas específicas, Japiassu (2006, p. 15) menciona:

O modo de pensamento ou de conhecimento fragmentado, monodisciplinar e simplesmente quantificador, tomando como critério de construção o ponto de vista (o paradigma) de um ramo do saber autodeterminado ou disciplinar, com todos os seus interesses subjacentes, é responsável pela prevalência de uma inteligência bastante míope ou cega na medida em que é sacrificada a aptidão humana normal de religar os conhecimentos em proveito da capacidade (também normal) de separar ou desconectar. 
Ora, o que se vê no fragmento anterior é a sintetização do que se busca no processo de ensino-aprendizagem, onde a função docente visa apresentar aos discentes uma diversidade de fontes de conhecimentos e instigá-los a beber nessas fontes, porém, deixando claro que há inúmeras outras fontes e formas de conhecimentos.

Ao narrar sobre a transdisciplinaridade, o autor destaca ainda a existência de conhecimentos entre, através e além (grifos do autor) das disciplinas, que alicerça a independência do aluno na busca e ampliação de conhecimentos.

O incentivo da busca por conhecimento, além das fronteiras das disciplinas, exige dos professores habilidades extras para direcionarem os professores em formação para um caminho de observação, de experimentação, o qual não é fácil, não é simplista, na verdade é muito complexo, e que não visa uma verdade absoluta, nem resposta única para uma investigação (Cunha, 1996).

Sobre a complexidade, Morin (2008, p.7) defende:

A palavra complexidade só pode exprimir o nosso embaraço, a nossa confusão, a nossa incapacidade de definir de maneira simples, de nomear de maneira clara, de pôr ordem nas nossas ideias.

Também o conhecimento científico foi durante muito tempo e permanece ainda frequentemente concebido como tendo por missão dissipar a aparente complexidade dos fenômenos a fim de revelar a ordem simples a que obedecem.

Ao analisar os desafios da formação e da prática docentes sob a égide do pensamento de Morin sobre complexidade, evidencia-se o caráter contínuo da formação docente, bem como se apregoa que a prática docente apresentará sempre novos desafios, os quais aparecem a partir das inovações de cunho social, econômico, cultural, tecnológico, etc., e que podem interferir no processo de ensino-aprendizagem, uma vez que exigem pensamentos e profissionais multidimensionais.

O Brasil é um país multicultural e o seu desenvolvimento está alicerçado principalmente na educação, assim, não há como se falar de um modelo educacional singular que não abarque as características plurais de um país tão vasto. Além disso, ao tratar sobre a educação brasileira, há que se pensar em um processo de formação voltado primordialmente para a aprendizagem dos alunos, levando em consideração todos os elementos que impedem o desenvolvimento da educação brasileira, a qual enfrenta os mesmos problemas há décadas, embora sejam constantemente criadas novas políticas públicas com o intuito de melhorar os índices educacionais.

Considerando-se que a sociedade encontra-se em evolução e transformação constantes, a escola e seus objetivos não podem ficar estagnados em contextos 
anteriores. Ao mesmo tempo em que os discursos apontam a escola como principal ferramenta de transformação da sociedade atual, percebe-se um descontentamento generalizado com os índices alcançados pelas escolas brasileiras a cada vez que são divulgados resultados de instrumentos de avaliação da educação básica.

Analisando a realidade da educação brasileira, percebe-se que há problemas que afetam a comunidade escolar como um todo, porém não se percebe uma preocupação pedagógica que promova interação entre a educação e a sociedade.

Professores, alunos e pais estão desmotivados, amarrados a paradigmas educacionais retrógrados, descontextualizados e que dificultam a evolução do processo de ensino-aprendizagem, como defende Maria C. Moraes (2011, p. 14): "Há um descontentamento crônico em relação à prestação de serviços educacionais [...] esse descontentamento vem aumentando [...] a escola não cumpre o seu papel, está dissociada do mundo e da vida".

Repensar a formação e a prática docentes é uma maneira de exercitar o cotidiano da produção e transmissão de conhecimentos. Não cabe ao professor, tampouco aos professores em formação, acharem respostas definitivas para as dúvidas que movem a educação. O seu papel é instigar os estudantes a quererem ir além, a transporem limites na busca pelo conhecimento.

É papel do professor promover uma conexão do mundo teórico com o prático, da combinação entre os diversos saberes e áreas, incentivando os alunos a irem além dos limites conteudistas determinados pela grade curricular. Desta forma, visa-se um novo paradigma educacional que enfrente os problemas da educação atual, que instigue o educando a ir além da disciplinarização/especialização, a qual produz saberes fragmentados que não incentivam a interação entre disciplinas e áreas diversas, conforme comungam Japiassu (2006), Morin (2008), Moraes (2011), dentre outros estudiosos.

A atualidade é feita de inovações, as quais estão presentes na vida das pessoas como um todo; a sociedade, em constante formação, aponta para transformações que requerem a quebra de paradigmas, a ruptura com tradicionalismos que foram suficientes para outros momentos, mas, que já não atendem os anseios da contemporaneidade, como referenciado a seguir:

Nos últimos quatro séculos, atiramo-nos à frenética tarefa de especializar nossas mentes. No início, num movimento compensatório salutar, já foi dito, cumprindo uma necessária e fundamental função histórico-cultural. Depois, por puro 
condicionamento dissociativo. Esclerosamo-nos no outro extremo da polaridade. Ser especialista tornou-se fado e fardo cultural. Unilateralidade de visão adquiriu status: desconectados de uma visão global, tornamo-nos sofisticados prisioneiros das frações. (CREMA; WEIL; D’AMBROSIO, 1994, p. 138).

Este excerto representa a justificativa para a necessidade de transformações no modelo educacional vigente, como forma de propiciar uma educação integrada com o momento atual, e que assim possa haver um diálogo entre o que se vive, ensina e aprende; uma contextualização que ajude a libertar o ser do aprisionamento das especialidades que impedem a interação com outras áreas do conhecimento.

O desafio de ensinar, independentemente da qualidade do processo formador, coloca ao professor o desafio de preparar os seus alunos para encarar o novo, devendo esclarecer aos educandos que a formação é uma constante, a qual estará sempre presente em sua prática profissional. O exercício profissional docente é complexo, assim como poderão ser complexos os desafios de elaborar novas metodologias cotidianamente para enfrentar as dificuldades da sala de aula e com isso modificar os paradigmas educacionais vigentes.

\section{NOVOS PARADIGMAS, NOVAS METODOLOGIAS}

Os rumos da educação brasileira na atualidade vêm despertando cada vez mais o interesse de estudiosos que buscam analisar os fenômenos que envolvem o processo de ensino-aprendizagem e, com isso, oferecer subsídios para a elaboração de políticas públicas, bem como o planejamento de ações pedagógicas voltadas para melhorar a qualidade da educação básica ofertada no País.

O disposto no artigo 205 da Constituição Federal (1988) prevê a educação como direito de todos, e lá também está estampada a obrigatoriedade do Estado e da família colaborarem para que esta ferramenta de transformação da sociedade de fato cumpra o seu papel de visar ao pleno desenvolvimento da pessoa, seu preparo para o exercício da cidadania e sua qualificação para o trabalho.

Ora, se a sociedade está mudando constantemente, se o conhecimento está em constante construção, se a formação é inerente ao mercado de trabalho e este também é evolutivo, é salutar que a formação do professor também acompanhe essa evolução e lhes faça perceber a necessidade de constante formação, independentemente da academia, de estar sempre aberto a novas metodologias que o ajude a contextualizar os componentes curriculares com a vida que o cerca. 
Daí a percepção de que a célula embrionária da transformação da prática docente está no seu processo de formação, sendo as licenciaturas terrenos férteis para a preparação profissional visando novos paradigmas e procedimentos metodológicos, que contribuam com o fortalecimento da participação da educação na construção da sociedade.

A Organização de Cooperação e Desenvolvimento Econômico (OCDE) é uma entidade internacional, focada na participação da educação no desenvolvimento das sociedades. Ela tornou-se referência nos estudos educacionais pelo mundo e, ao longo dos últimos anos, tem divulgado relatórios e documentos nos quais evidencia a prática docente como essencial para o desenvolvimento social. Assim, em um estudo publicado em 2004, como em muitos outros divulgados pela Organização nos anos seguintes, a OCDE destaca a importância formação docente:

\begin{abstract}
A qualidade do corpo docente é um fator de primeiro plano, quando um país, qualquer que seja, aspira a excelência de seu sistema educacional. Os professores constituem o centro do sistema escolar, e as pesquisas mais diversas confirmaram quanto a qualidade dos professores conta na aquisição dos alunos. É por isso que os poderes públicos levam tão a sério a melhoria da qualidade dos professores, para assegurar que todos os alunos se beneficiem de um bom ensino. (p. 1).
\end{abstract}

O foco na formação docente ainda está ganhando forças na educação brasileira. Reconhece-se a importância do papel do professor, entretanto, as políticas públicas ainda carecem de direcionamentos contextualizados para que realmente essa importância do professor, tão recorrente nos discursos, consiga ter reflexos em suas condições de trabalho, remunerações, e reconhecimento também por parte dos alunos, por exemplo, e assim contribuir de fato com um ensino de qualidade.

À universidade cabe a produção e transmissão de conhecimentos e, no Brasil, desde a autorização e regulamentação do funcionamento das universidades pelo governo de Getúlio Vargas através da Reforma Francisco Campos, na década de 1930, estabeleceu-se ser a universidade espaço de tessitura de conhecimentos, de experimentação científica e tecnológica com aplicações na vida social, sob a obrigatoriedade de não dissociar ensino, pesquisa e extensão, os quais são interdependentes e complementares, conforme disposto no artigo 207 da Constituição Federal (Brasil, 1988).

É a universidade que abastece o mercado de trabalho de profissionais, portanto, o seu currículo deve ser pensado levando-se em consideração as exigências profissionais inerentes ao contexto social do momento vivido. Nos cursos de formação 
docente, o currículo tem a função de aproximar a teoria e a prática pedagógicas, porém, sem reflexão, os relatórios de estágio não passarão de meras formalidades para a obtenção do título de professor e que em nada contribuirão para mudar o paradigma educacional em voga. De acordo com Pimenta et al (2005, p. 16):

As pesquisas em relação à formação inicial têm demonstrado que os cursos de formação, ao desenvolverem um currículo formal com conteúdos e atividades de estágios distanciados da realidade das escolas, numa perspectiva burocrática e cartorial que não dão conta de captar as contradições presentes na prática social de educar, pouco têm contribuído para gestar uma nova identidade profissional docente.

Entretanto, em se tratando da função docente, principalmente daqueles que atuam na educação básica, fica evidente que esse preceito constitucional nem sempre é cumprido integralmente, pois, em sua maioria, na escola básica brasileira não há espaço para a prática da pesquisa porque os professores estão muito ocupados com a integralização dos conteúdos curriculares, sem que haja relação com a experimentação e interação entre a pesquisa, a extensão e a sociedade.

O processo de formação educacional, seja ele básico ou superior, está embasado no tripé ensino, pesquisa e extensão, embora estes nem sempre sejam presentes nas instituições educacionais brasileiras. No entanto, eles são essenciais para o paradigma educacional atual onde o indivíduo bem formado e independente deve, além de ter conhecimentos, aplicá-los em suas vivências. Sobre a necessidade de mudanças nessa cultura escolar, Moraes (2011, p. 20) reforça a necessidade de rever o paradigma educacional vigente e adverte:

Se estamos preocupados em formar indivíduos autônomos, criativos, críticos, cooperativos, solidários e fraternos, mais integrados e harmoniosos, capazes de explorar o universo de suas construções intelectuais, teremos de optar por um tipo de paradigma educacional diferente dos modelos convencionais atuais, que por sua vez foram influenciados por determinadas correntes filosóficas ancoradas num determinado paradigma adotado pela ciência.

Talvez os professores que atuam com baixos salários, sem condições de trabalho por conta de estrutura e aparelhamento deficitários, além das salas superlotadas de alunos, até tenham consciência, quer pela sua formação ou até mesmo pela sua prática docente, da importância da integração entre ensino, pesquisa e extensão. Entretanto, estes se sentem vencedores por já conseguirem, nessas condições, cumprir os conteúdos curriculares estipulados para aquele período letivo.

Na sua prática docente o professor precisa despir-se dos hábitos, pré-conceitos e daqueles saberes absolutos (grifo nosso) de que o que se ensina nas escolas necessita 
de respostas absolutas e definitivas, portanto, sem direito ao contraditório, porque também ele, o professor, não teve, durante sua formação, a prática do método científico da experimentação como instrumento de aprendizado.

Melhorar a qualidade de ensino no país é tema frequente das políticas públicas e de pesquisas realizadas por estudiosos da educação brasileira; nos textos oficiais parece uma tarefa fácil, que basta instituir a política pública e tudo se resolve. Entretanto, o que se apreende sobre o assunto é que a formação docente requer ações muito mais profundas e requer a ruptura de um sistema tradicional de ensino, eivado de vícios, conhecimentos e práticas intocáveis, estruturação, ideologias e legislações descontextualizadas, conforme Marin e Giovanni (2007).

O paradigma educacional vigente na atualidade ainda não se libertou por completo do engessamento provocado por um modelo de ensino tradicional, que não permite uma observação/problematização da escola confrontando essa problematização com os referenciais teóricos e sua aplicação na realidade vivida, no social, segundo a obra Estratégias de ensino-aprendizagem, de Bordenave e Pereira (1994). Não seriam estas as funções do estágio supervisionado aplicado nas licenciaturas?

\section{O ESTÁGIO SUPERVISIONADO NAS LICENCIATURAS}

A metodologia da observação da prática docente - o estágio supervisionado permite aos futuros professores, baseados na realidade das salas de aulas, fazer uma avaliação das práticas pedagógicas aplicadas, e assim refletir a ação docente, buscando em situações reais, identificar gargalos do processo de ensino-aprendizagem.

As observações dos estagiários são transformadas em questionamentos/problematizações, registram a metodologia empregada, selecionam as práticas que de fato contribuem e aquelas dispensáveis à prática docente, confrontandoas com a teorização e reflexões dos relatórios gerados a partir dessa experiência e assim melhorar a prática docente, como também se vê em Bordenave (1994, p. 25). Porém, se não forem apresentados aos regentes observados, os relatórios de estágio pouco contribuirão com a mudança da realidade observada pelo estagiário.

Ao defender a busca por um novo paradigma para a educação brasileira, Moraes (2011, p. 29) nos leva a refletir sobre a produção de ambientes de aprendizagem que se justaponham à realidade vivida pelas nossas crianças e aprendizes. Isso inclui outros ramos da vivência que não estritamente o educacional, porque a escola prepara as 
pessoas para a vida, incluindo inúmeros outros saberes que não apenas aqueles advindos do processo escolar, como estarem preparadas para resolver possíveis problemas sociais a partir de novas interpretações das vivências, da natureza e do homem.

Ao analisar relatórios de estágio e as teorias sobre a formação e prática docente, não é difícil perceber que o paradigma educacional que ora se apresenta coloca o professor diante de novos desafios, mas não lhe permite ou, ao menos, não lhe dá condições para o enfrentamento dessas dificuldades que acabam se tornando gargalos do ensino-aprendizagem.

O modelo tradicional de ensino pode ter sido utilizado com sucesso em outros momentos, contudo, na atualidade, onde muitas unidades escolares não têm infraestrutura adequada, professores com formação deficitária e até mesmo uma parcela considerável sem formação superior, salas com uma quantidade elevada de alunos, bem como diferentes níveis de conhecimento por parte dos alunos, engessa o processo de aquisição e transmissão de conhecimentos. São problemas que ficam apenas registrados nos relatórios de estágio dos futuros professores sem provocar nenhuma ação para reverter esse paradigma educacional ultrapassado, distante da situação atual.

Assim, a justificativa para a disciplina de estágio supervisionado vai além do simples registro da situação encontrada nas escolas-campo; os relatórios de estágios são documentos a partir dos quais devem sair inovações que possam contribuir com a prática do docente observado e assim melhorar a qualidade da educação oferecida, como a inserção da interdisciplinaridade, transdisciplinaridade e a multidisciplinaridade, como ferramentas para um novo modelo educacional capaz de diminuir as distâncias entre a teoria e a prática docentes.

Trechos de relatórios de estágio retirados da dissertação de Mestrado em Educação de Luana Amoroso Daniel (2009) retratam a necessidade de interação entre os estagiários (futuros professores) e os professores regentes, conforme excertos a seguir:

Acredito que, é somente nesse movimento de transitar por entre o saber e o saber fazer, de idas e vindas, por entre a teoria estudada nas diferentes disciplinas do curso e a prática observada e/ou participada no ambiente escolar, em que os professores exercem, realmente, a sua prática profissional, que é possível construir uma prática de estágio curricular que seja significativa para o processo de formação inicial de professores. (p. 76).

Os professores hoje têm muitos desafios para enfrentar. Como já disse no passado tudo era mais fácil, mas hoje a universidade tem o dever de preparar os professores para enfrentar todas as diversidades da profissão, mas infelizmente isso ainda não 
acontece por isso acredito que ser parceiro de meus estagiários é fundamental. [...] ao abrir suas portas, a escola deixa mais claro os pontos que merecem uma atenção maior, mostra que nem tudo é lindo como parece nessa profissão, mas que muito pode ser feito por nossas mãos. (PR3). (p. 97).

Sim, todos nós somos formadores e formados desde que abramos o nosso espírito ao outro. [...] Somo parceiros nessa luta pela melhora da educação. (PR1). (p. 109)

[...] aprender é uma arte e um prazer. Quando nos propomos a isso todos somos formadores uns dos outros, mesmo que o meio não reconheça isso. (PR2). (p. 109).

O que se pode inferir dos relatos acima entre os estagiários e os regentes é que os relatórios de estágio são documentos importantes, capazes de transformar positivamente a prática docente, podendo ainda, ao mesmo tempo, servir de balizadores do processo de formação continuada dos professores que já estão em sala de aula e também um reforço prático dos ensinamentos passados aos futuros professores.

\section{INTER/TRANS/MULTIDISCIPLINARIDADE NA EDUCAÇÃO}

O momento presente é de profundas transformações na humanidade, fato este que é objeto de pesquisa de grandes pensadores como Morin (2008), D’Ambrósio (1997), Boaventura dos Santos (2011), dentre muitos outros que buscam entender e explicar os fenômenos existentes na composição da sociedade atual e que perpassam a educação.

A figura a seguir, Transdisciplinaridade - Modelo de Jantsch mostra uma síntese da conceituação da interdisciplinaridade, transdisciplinaridade e multidisciplinaridade, termos que chegam até a causar divergências no entendimento do que vem a ser cada uma; a demonstração gráfica esclarece as diferenças que as mesmas têm na prática:

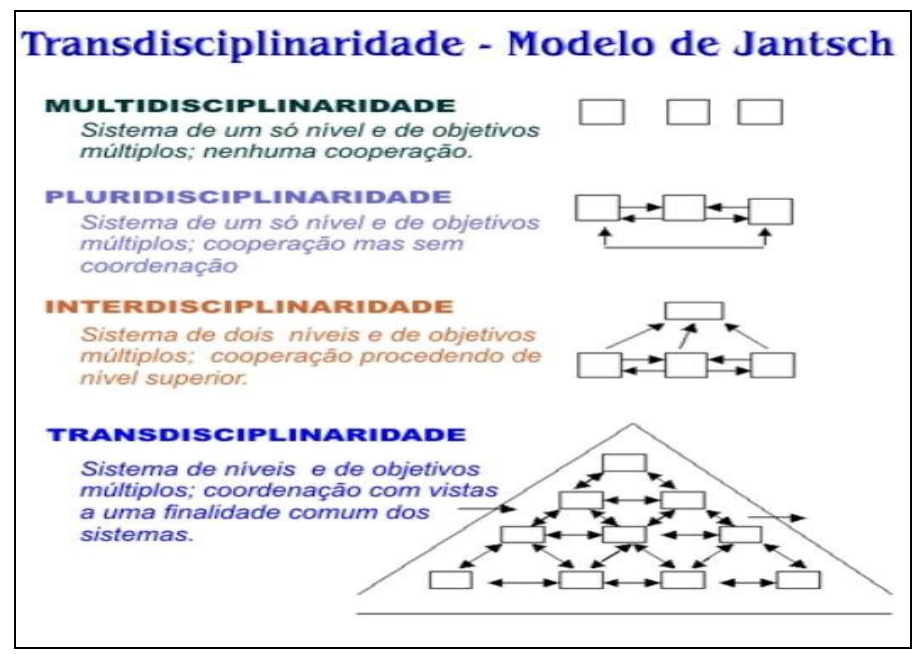

Figura 1: Transdisciplinaridade - Modelo de Jantsch 
As definições constantes na figura acima mostram a interação entre as disciplinas como elemento fundamental no processo de produção e transmissão de conhecimentos. As interações presentes no Modelo de Jantsch ressaltam as contribuições que a cooperação entre os diversos saberes pode trazer para a formação do indivíduo a partir da multidisciplinaridade, interdisciplinaridade e transdisciplinaridade, evidenciando que o homem sempre tem algo novo a aprender e a ensinar com base nos conhecimentos produzidos pela interação entre saberes diversos.

A multidisciplinaridade compreende juntar, justapor ou aproximar as disciplinas sem, no entanto, colocar próximos os profissionais de cada disciplina, sem fazer com que os detentores do saber disciplinar observem, reflitam e discutam à luz de seus aportes teóricos; assim, as disciplinas se encontram, porém, os especialistas que as representam não interagem.

Ao tratar sobre a multidisciplinaridade, Japiassu (2006, p. 39) também ressalta a aglomeração de diversos estudiosos com o intuito de estudar o objeto de uma disciplina, entretanto, sem que haja a interação entre as disciplinas que compõem as grades curriculares.

Para o autor, na pesquisa multidisciplinar pesquisadores de diferentes áreas de conhecimento ou diferentes especialidades colocam "em relação os diversos aspectos que podem revestir a divisão do trabalho para estudar o objeto de uma disciplina", podendo ser, inclusive, uma pesquisa interdisciplinar.

O conceito de multidisciplinar em D’Ambrósio (2007, p. 19) destaca a pluralidade dos saberes centrados nas disciplinas, mas critica a falta de transitoriedade entre elas; nas palavras do autor, as grades curriculares são "gaiolas epistemológicas" por manterem os alunos presos, de maneira organizada, no ensino compartimentalizado sem interação entre os conhecimentos diversos.

Vive-se um período de percepção da interdependência das coisas, para Renée Weber (1991, p. 23):

A percepção da unidade e da interligação de todos os seres leva - se é consistente a uma empatia para com o próximo. Expressa-se como uma reverência à vida, à compaixão, ao sentimento de fraternidade com a humanidade sofredora e uma tendência a curar a terra ferida e os seus habitantes. Todos os místicos e, virtualmente todos os cientistas ressaltam, nesses diálogos, conexão entre sua visão do todo e seu senso de responsabilidade para com ele. 
A interdependência mencionada acima concorda com a definição de Fazenda (2006, p. 43) para interdisciplinaridade:

Interdisciplinaridade é uma exigência natural e interna das ciências, no sentido de uma melhor compreensão da realidade que elas nos fazem conhecer. Impõe-se tanto à formação do homem quanto às necessidades de ação.

A interdisciplinaridade, em síntese, propõe o diálogo entre disciplinas diversas, mostrando que a informação e o conhecimento podem estar além delas, e que o relacionamento entre disciplinas diferentes promove uma interdependência capaz de gerar ainda mais conhecimentos e aproximá-los da prática cotidiana, conforme (WEIL et al, 1993).

Os novos desafios educacionais fazem bater de frente posicionamentos antagônicos, verdades antes indiscutíveis passam a ser questionadas, assim como os limites impostos pela disciplinarização, pela existência de disciplinas individuais, como caixinhas de conhecimentos. Segundo Santomé (1998, p. 70),

Trata-se da construção de um sistema total, sem fronteiras sólidas entre as disciplinas, ou seja, de uma teoria geral de sistemas ou de estruturas, que inclua estruturas operacionais, estruturas de regulamentação e sistemas probabilísticos, e que una estas diversas possibilidades por meio de transformações reguladas e definidas.

Esse saber construído, ao considerar o caráter contínuo da formação do ser humano, com um trânsito livre entre as disciplinas, leva à percepção de que outros paradigmas irão surgir e com eles a necessidade de novos olhares, novas reformulações, novas práticas pedagógicas.

Assim, D’Ambrósio (2007, p. 14) defende que “"[a] transdisciplinaridade, assumindo a inconclusividade do ser humano, rejeita a arrogância do saber concluído e das certezas convencionadas e propõe a humildade da busca permanente.”, o que também reforça a ideia dos novos paradigmas e novas metodologias e a flexibilidade para um constante aprendizado em prol da qualidade da educação que se oferece.

O processo de ensino e aprendizado está em construção, ou pelo menos depende de ações transformadoras da transdisciplinaridade, ou seja, da "articulação dos saberes das ciências, das artes, da filosofia, das tradições sapienciais e da experiência, que são diferentes modos de percepção e descrição da realidade", conforme Santos e Sommerman, (2009, p. 73). Desta forma, a transdisciplinaridade retrata a liberdade de interação entre os diversos saberes como forma de ampliar os conhecimentos que são frutos das relações e interações do homem com a realidade. 
De acordo com D’Ambrósio (1997 p. 80), o cerne da ideia de transdisciplinaridade encontra guarida no reconhecimento de que todas as culturas são importantes e não há espaço nem tempo culturais, tampouco existe supremacia entre elas, não existem mais certas ou mais erradas, e todas têm nexo com a realidade. A transdisciplinaridade é, portanto, o momento de abertura das gaiolas.

A argumentação de Magalhães (2011, p. 388) ressalta o caráter integrador da transdisciplinaridade na retirada das barreiras causadas pela disciplinarização, ou seja, "[a] transdisciplinaridade ajuda ao exigir o cruzamento de especialidades, o trabalho nas interfaces, a superação das fronteiras, a migração do conceito de um campo de saber para outro (...)", fomentando assim a construção do conhecimento generalizado.

Ao discorrer sobre a transdisciplinaridade, D’Ambrósio (1997 p. 89) afirma que "[s]e pretendemos uma educação abrangente, envolvida com o estado do mundo, abrindo perspectivas para um futuro melhor, temos que repensar nossa prática, nossos currículos.”; desta forma, como não destacar a urgente necessidade de reformulação dos componentes curriculares que integram os cursos de formação docente, com o intuito de promover a interação entre a educação e a globalização em voga na atualidade.

Autores como Morin (2007a), Fazenda (2006), D’Ambrósio (1997), dentre outros, discutem a necessidade de se considerar a Complexidade como um paradigma capaz de orientar o desenvolvimento científico e cognitivo com fins de reposicionar as pessoas diante das urgentes mudanças na sociedade, principalmente no tocante à produção e transmissão de conhecimentos.

Considerando-se a máxima de que a educação é um dos principais caminhos para essa revolução, embora isso não seja uma fórmula mágica definitiva para minimizar os problemas da educação. Não são as inovações da tecnologia, por exemplo, que sozinhas irão melhorar a qualidade da educação brasileira, o que fica evidente na defesa de Perrenoud (1995, p. 15):

[...] a inovação não se traduz no recurso a equipamentos tecnologicamente sofisticados e atualizados, mas implica uma mudança bem mais profunda, intrinsecamente ligada com a criatividade, com a capacidade de produzir e de concretizar ideias novas e originais.

A argumentação de Perrenoud expõe algo que há muito tempo já faz parte dos discursos de estudiosos, de universidades e até de professores; entretanto, ainda não está retratada nas avaliações dos rendimentos alcançados pela educação brasileira, 
tampouco provoca alterações nos currículos dos programas de formação docente e mais uma vez, teoria e prática permanecem em lados opostos.

\section{CONSIDERAÇÕES FINAIS}

Em um período de tantas transformações, tantos elementos influenciando positiva e negativamente a educação, coerente seria valorizar todas as formas de conhecimento. Abrir-se para o novo é fazer do magistério, seja na educação básica ou no ensino superior, um exercício das novidades de uma educação viva, capaz de unir conhecimentos e vivências.

Ao professor cabe a missão de não parar no tempo, de não se permitir ser excluído do rol de contribuintes com a construção de uma escola que efetivamente contribui para a formação de uma sociedade com conhecimento, com capacidade crítica e autônoma.

Exigência das licenciaturas, a disciplina de estágio supervisionado é uma espécie de laboratório para que os futuros professores vejam de perto a realidade que irão encontrar na sua profissão. As observações registradas nos relatórios precisam ganhar vida, precisam refletir e provocar mudanças de atitudes para que o indivíduo possa oferecer o seu melhor para a educação.

Os teóricos aqui referenciados, sejam contemporâneos ou de períodos anteriores, ao tratarem sobre o tema da formação de professores são unânimes em defender uma maior proximidade entre os programas de formação docente e a realidade do momento vivido, bem como apontam os currículos dos cursos de formação como descontextualizados da prática pedagógica das salas de aulas.

As discussões acerca dos conceitos de multidisciplinaridade, interdisciplinaridade ou transdisciplinaridade são relativamente novas, talvez estes termos não tenham sido estudados por boa parte dos professores em atividade atualmente, assim, os programas de formação continuada, a troca de informações entre estagiários e professores regentes, bem como a vontade do professor regente de estar sempre se atualizando, são elementos que podem contribuir com a promoção de uma educação mais próxima da realidade vivida.

A docência na atualidade parece ser mais fácil quando as gaiolas das disciplinas citadas por D’Ambrósio permanecem fechadas, assim, cada professor deve cuidar apenas da sua especialidade, deixando a interdisciplinaridade, transdisciplinaridade ou 
multidisciplinaridade de lado, como se estas não fossem importantes para a formação do indivíduo.

A complexidade defendida por Morin como sendo útil para a independência do ser na busca pelo conhecimento totalizante e não fragmentador, torna-se resistência na prática docente; a realidade encontrada na sala de aula pelos professores em nada se iguala à profissão nobre dos discursos teóricos e políticos, onde a teoria e a prática deveriam andar lado a lado melhorando os índices educacionais brasileiros.

São tantas as metas estabelecidas que refletir a prática docente, a formação continuada e elaborar novas metodologias, dentre outras ações docentes, tornam-se desafios a mais para os professores. É inegável que a formação e a prática docentes precisam ser repensadas, necessitam de reformulações que aproximem a escola e seus ensinamentos da realidade vivida na atualidade, para, desta forma, melhorar o processo de ensino-aprendizagem da educação brasileira.

\section{REFERÊNCIAS}

BORDENAVE, J. E. D. O que é participação? Coleção Primeiros Passos. São Paulo: Brasiliense, 1994.

BORDENAVE, J. D.; PEREIRA, A. M. Estratégias de ensino-aprendizagem. 14. ed. Petrópolis: Vozes, 1994.

BRASIL. Constituição (1988). Constituição da República Federativa do Brasil.Belém: Basa, 1988.

Lei no 9.394, de 20 de dezembro de 1996. Estabelece as Diretrizes e Bases da Educação Nacional. Diário Oficial da República Federativa do Brasil, Brasília, DF, n. 248, 23 dez. 1996.

CONFERÊNCIA MUNDIAL SOBRE O ENSINO SUPERIOR, 1998, Paris. Tendências da educação superior para o século XXI. Brasília: Crub, 1999.

CREMA, R.; WEIL, P.; D’AMBRÓSIO, U. Rumo à nova interdisciplinaridade. São Paulo: Summus, 1994.

CUNHA LA. A universidade temporã. Rio de Janeiro: Francisco Alves, 1986.

D’AMBRÓSIO, U. Transdisciplinaridade. São Paulo: Palas Athena, 1997.

Educação para compatibilizar desenvolvimento e sustentabilidade. In: Desenvolvimento e Meio Ambiente, n. 15, p. 11-20, jan./jun. 2007. Editora UFPR. 
DANIEL, Luana Amoroso. O professor regente, o professor orientador e os estágios supervisionados na formação inicial de futuros professores de Letras. 2009. 152p. Dissertação de Mestrado em Educação. Universidade Metodista de Piracicaba.

FAZENDA, I. Interdisciplinaridade: qual o sentido? São Paulo: Paulus, 2003. (Coleção Questões fundamentais da educação: 2 / Coordenação Ecleide Cunico Furlanetto).

JANTSCH, A.P.; BIANCHETTI, L. Interdisciplinaridade: para além da filosofia do sujeito. Petrópolis: Vozes, 1995.

JAPIASSU, N. O sonho transdisciplinar: e as razões da filosofia / Hilton Japiassu. Rio de Janeiro: Imago, 2006.

LUCKESI, C. Formação do educador sob uma ótica transdisciplinar. Revista ABC EDUCATIO, São Paulo: Editora CRIAP, v. 04, n. 29, p. 1-17, nov. 2003.

MARIN, A. J. GIOVANNI, L. M. Expressão escrita de concluintes de curso universitário para formar professores. Cadernos de Pesquisa, v. 37, p. 15-41, 2007.

MORAES, M.C. O paradigma educacional emergente / Maria Cândida Moraes. 16 ed. - Campinas, SP : Papirus, 2011.

MORIN, E. A cabeça bem-feita. Repensar a reforma, reformar o pensamento. 15 ed. Rio de Janeiro: Bertrand Brasil, 2008.

MAGALHÃES, S. M. O. Crise paradigmática e a transformação da sala de aula universitária. Revista Travessias. ISSN: $1982-5935$ (versão eletrônica). Vol. 5, No 2 (2011). Universidade Estadual do Oeste do Paraná, Cascavel - Paraná, 2011.

OCDE. La qualité du personnel enseignant. 2004. Disponível em: http://www.oecd.org/dataoecd/0/8/31589487.pdf. Acesso em: 12/2014.

PERRENOUD, P. (1995). O ofício do aluno e o sentido do trabalho escolar. Porto: Porto Editora.

PIMENTA, S. G. et al. (Org.). Saberes pedagógicos e atividade docente. 4. ed. São Paulo: Cortez, 2005.

SANTOMÉ, J. T. Globalização e Interdisciplinaridade: o Currículo Integrado. 1. Ed. Porto Alegre: Artes Médicas, 1998.

SANTOS, A.; SOMMERMAN, A. (Org.). Complexidade e transdisciplinaridade: em busca da totalidade perdida. Porto Alegre: Sulina, 2009.

SANTOS, S.B.de. A Universidade no Século XXI: Para uma reforma democrática e emancipatória da Universidade / Boaventura de Sousa Santos. - 3. Ed. - São Paulo : Cortez, 2011. - (Coleção questões da nossa época ; v. 11 
TAVARES, M. Em torno de um novo paradigma sócio-epistemológico. Rev. Lusófona de Educação [online]. 2007, n.10, pp. 131-137. ISSN 1645-7250.

WEBER, R. (1991). Diálogos entre cientistas e sábios: A busca da unidade. São Paulo: Cultrix.

WEIL, P.; D'AMBROSIO, U.; CREMA, R.. Rumo à nova transdisciplinaridade: sistemas abertos de conhecimento. 2. ed. São Paulo: Summus Editorial, 1993.

\section{OS AUTORES}

Ruberval Rodrigues de Sousa é doutorando em Letras pela Universidade Federal do Tocantins, mestre em Desenvolvimento Local pela Universidade Católica Dom Bosco, especialista em Metodologia de Ensino de Língua Inglesa pela UFT, bacharel em Comunicação Social pela Fundação Universidade do Tocantins e licenciado em Letras pela Fundação Universidade do Tocantins. Atualmente é secretário executivo na Universidade Federal do Tocantins - UFT e professor na Secretaria de Estado da Educação do Tocantins - SEDUC/TO.

E-mail: rubervalrs@gmail.com

Thyago Phellip França Freitas é arquiteto e urbanista, mestre em Ciências do Ambiente (UFT), com MBA em Gestão de Projetos e Cidades (UFT) e em Gestão de Pessoas (UFT). É arquiteto e urbanista da Secretaria de Estado da Educação do Tocantins e professor do curso de Arquitetura e Urbanismo do Centro Universitário Luterano de Palmas.

Email: thyagophellip@ceulp.edu.br 